\title{
Influence of acrylamide monomer addition to the acrylic denture-base resins on mechanical and physical properties
}

\author{
Elif Aydogan Ayaz and Rukiye Durkan
}

The aim of the study was to evaluate the effect of adding acrylamide monomer (AAm) on the characterization, flexural strength, flexural modulus and thermal degradation temperature of poly(methyl methacrylate) (PMMA) denture-base resins. Specimens $(n=10)$ were fabricated from a conventional heat-activated QC-20 (Qc-) and a microwave heat-activated Acron MC (Ac-) PMMA resins. Powder/ liquid ratio followed the manufacturer's instructions for the control groups (Qc-c and Ac-c) and for the copolymer groups, the resins were prepared with $5 \%(-5), 10 \%(-10), 15 \%(-15)$ and $20 \%(-20)$ acrylamide contents, according to the molecular weight ratio, respectively. The flexural strength and flexural modulus were measured by a three-point bending test. The data obtained were statistically analyzed by Kruskal-Wallis test $(\alpha=0.05)$ to determine significant differences between the groups. The chemical structures of the resins were characterized by the nuclear magnetic resonance spectroscopy. Thermal stabilities were determined by thermogravimetric analysis (TGA) with a heating rate of $10^{\circ} \mathrm{C} \cdot \mathrm{min}^{-1}$ from $35^{\circ} \mathrm{C}$ to $600{ }^{\circ} \mathrm{C}$. Control groups from both acrylic resins showed the lowest flexural strength values. Qc-15 showed significant increase in the flexural strength when compared to Qc-c $(P<0.01)$. Ac-10 and Ac-15 showed significance when compared to Ac-c $(P<0.01)$. Acrylamide incorporation increased the elastic modulus in Qc-10, Qc-15 and Qc-20 when compared to Qc-c $(P<0.01)$. Also significant increase was observed in Ac-10, Ac-15 and Ac-20 copolymer groups when compared to $A c-c(P<0.01)$. According to the ${ }^{1} \mathrm{H}$-nuclear magnetic resonance (NMR) results, acrylamide copolymerization was confirmed in the experimental groups. TGA results showed that the thermal stability of PMMA is increased by the insertion of AAm.

International Journal of Oral Science (2013) 5, 229-235; doi:10.1038/ijos.2013.69; published online 13 September 2013

Keywords: acrylamide; denture resin; nuclear magnetic resonance; poly(methyl methacrylate); thermogravimetric analysis; threepoint bending test

\section{INTRODUCTION}

Polymers are used in the manufacture of dentures that rest on the soft tissues of the mouth, artificial teeth, repair materials, orthodontic splints and crown restorations. ${ }^{1}$ The most commonly used polymer in prosthesis is acrylic resin, which is based on poly(methyl methacrylate) (PMMA). PMMA was initially discovered and evaluated in the 1860s. In the late 1930s, heat-polymerized acrylic resins were introduced for use in denture bases by Walter $\mathrm{H}$. Write. ${ }^{2-3}$ In the following years, microwave polymerization was introduced by $\mathrm{Nishii}^{4}$ and has become a popular alternative to the conventional water bath method. Acrylic resins used as the denture materials have been supplied in various forms such as powder-liquid, gels, and sheets or blanks. Currently, the most popular form is the powder-liquid type, which contains acrylic polymer beads, monomer, initiator, inhibitor, pigments, accelerator, plasticizer and crosslinking agent. ${ }^{3}$

The fracture of PMMA denture bases is a common clinical problem, which frequently requires repair. ${ }^{5}$ Because denture base polymers are subjected to various forces that occur in the oral environment, ${ }^{5-6}$ high mechanical property is one of the most important requirements for successful denture base materials of the edentulous patients. PMMA is the ideal material for denture bases because it satisfies most of the requirements such as adequate strength, satisfactory thermal properties, dimensional stability, insolubility in oral fluids, acceptable aesthetics, ease of handling and moderate cost. ${ }^{7}$ However, PMMA is susceptible to fracture after periods of clinical use. ${ }^{8}$

The denture base resin is subjected to various stresses during function, including the compressive, tensile and shear stresses. ${ }^{9-10}$ Fractures in the dentures result from two different types of forces, namely, impact and flexural fatigue. ${ }^{11}$ Most fractures of a complete denture occur inside the mouth due to the repeated flexural masticatory forces during function, primarily because of resin fatigue. Outside the mouth, high-impact forces as a result of dropping the prostheses cause the fractures. $^{9-12}$

The need to produce stronger and more fracture-resistant denture base materials has resulted in different reinforcement methods. Numerous attempts have been reported to solve these problems and 
to improve the mechanical properties of dental polymers, but most of them have not been transferred into clinical dentistry because of the processing difficulties and the high cost. One of the common reinforcing methods is the use of metal wires embedded in the prosthesis; however, the poor adhesion between the acrylic resin and the metal wires makes this technique disadvantageous. ${ }^{13}$ Another examined method is to reinforce the PMMA dentures with various fibers, such as carbon and glass fibers. Carbon fibers are useful in strengthening PMMA; however, the difficulty in polishing and the poor esthetics lead to clinical problems. Glass fibers, which are the most commonly used fibers, improve the mechanical properties of the denture base polymers, and they are esthetically pleasing, but their high cost limits their routine clinical use. ${ }^{14-15}$ Chemical modification of the PMMA, which uses a copolymerization mechanism, has been tested and has improved the impact strength of the denture base resins. ${ }^{5,16}$

An alternative to solve the problem is to incorporate some types of monomers to PMMA. Recently, there has been increasing interest in using various types of monomers in polymeric dental materials to optimize the properties and to provide patient satisfaction. Rodford ${ }^{17}$ used low-molecular-weight butadiene styrene monomer with PMMA and reported an increase in the impact strength of the denture bases, but in further studies, a decrease was observed in the flexural strength. ${ }^{18}$ Ellakwa et al. ${ }^{19}$ added aluminum oxide fillers to PMMA to increase the flexural strength and the thermal diffusivity of the material. However, none of the polymers or copolymers possess all of the desired properties for denture bases, and further studies of the resin reinforcement are still in progress.

Various types of monomers can be used, and they provide different benefits such as an antimicrobial effect. Several authors attempted to combine antifungal or antiseptic monomers with temporary soft liners or with denture acrylic resins. ${ }^{20-21}$ Cunha et al..$^{22}$ incorporated a fluoroalkyl methacrylate monomer to PMMA; Puri et al. ${ }^{23}$ used a phosphate-containing monomer (ethylene glycol dimethacrylate phosphate) to improve the physical properties of the denture base resins.

The knowledge of the material composition is important to evaluate utility and application potential of the material. The polymer composition and its distribution can be determined using spectroscopic analyses. The most common method is nuclear magnetic resonance (NMR) spectroscopy, which can be used to obtain the physical, chemical and structural information of the molecules. The structure of dental resins can be determined by studying the peaks of the NMR spectra. $^{24-25}$

Stereoscopic techniques have become an increasingly available and powerful tool to understand the nature of dental materials. NMR is an important, established and often essential tool to understand several important aspects of polymeric materials that cannot easily be obtained using other techniques. Characterization of dental materials using NMR is not new. Over the past 30 years, many researchers have used this technique for several investigations. He et al. ${ }^{26}$ used antibacterial agents in methacrylate dental composites to evaluate the antibacterial activity and they characterized the structure of the materials using NMR.

Thermogravimetric analysis (TGA) has been widely used to investigate the decomposition characteristics of many materials. It is a type of testing method performed on samples that determines the changes in weight in relation to a temperature program. ${ }^{27}$

A variety of physical properties can be used to assess the strength of denture materials. One of the most common tests is the flexural strength, which is the force needed to deform the material to fracture or an irreversible yield. Given the function of a denture base in a removable prosthesis, high flexural strength and flexural modulus would help resisting the torsional forces in function, which leads to a longer clinical service life for the prosthesis. ${ }^{18}$

The aim of the present study is to evaluate the effect of adding acrylamide monomer (AAm) on the characterization, flexural strength, flexural modulus and thermal degradation temperature of PMMA-based denture resins.

\section{MATERIALS AND METHODS}

In this study, the specimens were fabricated from one heat-polymerized and one microvawe-polymerized PMMA denture resins: QC-20 (Dentsply Ltd., Addlestone, UK) and Acron MC (GC Lab Technologies Inc., Alsip, Japan) (Table 1). The monomer liquid of the resin was a mixture of methylmethacrylate (MMA) containing glycole dimethacrylate as the crosslinker and benzoyl peroxide as the initiator. AAm was a particulate formed and dissolved by the MMA monomer (Merck, Hohenbrunn, Germany).

\section{Fabrication of specimens}

Ten specimens from each group $(n=10)$ were prepared for the mechanical tests. A three-point bending test was performed according to the ISO/DIS 1567 International Standard. ${ }^{28}$ Stainless steel models with dimensions of $64 \times 10 \times 3.3 \mathrm{~mm}^{3}$ were prepared to mold specimens.

For the control groups, the powder/liquid ratio was maintained as recommended by the manufacturers. In the copolymer groups, the resins were prepared with 5\%,10\%,15\% and $20 \%$ acrylamide contents according to the molecular weight ratios, respectively (Table 2). First, the particulate AAm was added to the liquid MMA monomer, and a dissolved monomer mixture was obtained. Then, the powder resin was added to the dissolved liquid, and the experimenters waited in a standard time of $10 \mathrm{~min}$ for the mixture to become doughy. The heat-polymerized acrylic resin specimens were polymerized in a thermally controlled autoclave device (QT $4060 \mathrm{~V}$; Nuve, Istanbul, Turkey) at $60{ }^{\circ} \mathrm{C}$ for $30 \mathrm{~min}$ to activate the initiator, and the final polymerization was performed at $130{ }^{\circ} \mathrm{C}$ for $20 \mathrm{~min}$. The microwave-polymerized resin samples were polymerized in a microwave oven (Vestel, Goldstar, Turkey) at $500 \mathrm{~W}$ for $3 \mathrm{~min}$. The acrylic resins were bench-cooled before deflasking; then they were polished on both surfaces using an automatic polishing machine (Grin PO $2 \mathrm{~V}$ grinderpolisher; Metkon A.Ş., Bursa, Turkey). All specimens were stored in a distilled water bath at $37^{\circ} \mathrm{C}$ for $(48 \pm 2)$ h before testing.

Table 1 Composition and manufacturers of the materials used in this study

\begin{tabular}{|c|c|c|c|}
\hline Material & Manufacturer & Chemical composition & Polymerization procedure \\
\hline QC-20 & Dentsply Ltd., Addlestone, UK & $\begin{array}{l}\text { Methyl methacrylate (methyl-n-butyl) copolymer, } \\
\text { ethylene glycole dimethacrylate, benzoile peroxide, } \\
\text { N,N-dimethyl p-toludine, hydroquinone }\end{array}$ & $\begin{array}{l}60{ }^{\circ} \mathrm{C} \text { for } 30 \text { min followed by } 130^{\circ} \mathrm{C} \text { for } \\
20 \text {-min heat polymerization }\end{array}$ \\
\hline Acron MC & $\begin{array}{l}\text { GC Lab Technologies Inc., } \\
\text { Alsip, Japan }\end{array}$ & $\begin{array}{l}\text { Methyl methacrylate, ethylacrylate copolymer, } \\
\text { benzoyl peroxide, N-dimethyl p-toludine, hydroquinone }\end{array}$ & $\begin{array}{l}500 \text { W 3-min microwave } \\
\text { polymerization }\end{array}$ \\
\hline Acrylamide & Merck, Hohenbrunn, Germany & Acrylamide monomer & - \\
\hline
\end{tabular}


Table 2 Group codes of control and copolymer resin specimens

\begin{tabular}{lcccc}
\hline & \multicolumn{4}{c}{ Copolymer groups } \\
\cline { 2 - 5 } Control groups & $\begin{array}{c}5 \% \\
\text { copolymer }\end{array}$ & $\begin{array}{c}10 \% \\
\text { copolymer }\end{array}$ & $\begin{array}{c}15 \% \\
\text { copolymer }\end{array}$ & $\begin{array}{c}20 \% \\
\text { copolymer }\end{array}$ \\
\hline QC-20 (QC-c) & Qc-5 & Qc-10 & Qc-15 & Qc-20 \\
Acron MC (Ac-c) & Ac-5 & Ac-10 & Ac-15 & Ac-20 \\
\hline
\end{tabular}

\section{Three-point bending test}

The flexural strength and flexural modulus were measured using a three-point bending test (Llyod Instruments, LRX, Fareham Hant, UK). The specimens were placed on jigs that were $50 \mathrm{~mm}$ apart, which represents the space between the maxillary molars in a complete denture. A load with a crosshead speed of $5 \mathrm{~mm} \cdot \mathrm{min}^{-1}$ was applied to the center of the specimens until fracture occurred. The flexural strength (FS) was calculated using the formula $\mathrm{FS}=3 F /\left(2 b h^{2}\right)$ where $F$ is the maximum load applied, $l$ is the span length $(50 \mathrm{~mm}), b$ is the width of the specimen $(10 \mathrm{~mm})$ and $h$ is the thickness of the specimen $(3.3 \mathrm{~mm})$. The flexural modulus (FM) was calculated using the formula FM= $F l^{3} /\left(4 b h^{3} d\right)$ where $d$ is the deflection.

\section{Statistical analysis}

The data were analyzed using SPSS for Windows 11.5 (SPSS Inc., Chicago, IL, USA). The results were tested regarding to the normality of distribution with the Shapiro-Wilk test and the homogeneity of variance using the Levene test. The data were not normally distributed and presented heterogeneous variances, which indicates that a nonparametric analysis should be used. All analyses were performed at a $95 \%$ confidence level $(\alpha=0.05)$. The mean values and the standard deviations of the flexural strength and flexural modulus for each group were calculated to compare the control groups with the copolymers of the resins. To determine the significant differences between the groups, the Kruskal-Wallis test was performed.

\section{NMR spectroscopy}

The ${ }^{1} \mathrm{H}$-NMR spectra of the control groups and the copolymers were recorded using a digital NMR spectrometer (Bruker DSX 400; Bruker Biospin GmbH, Karlsruhe, Germany). A 20-mg resin sample was dissolved in $1 \mathrm{~mL}$ of deuterated chloroform $\left(\mathrm{CDCl}_{3}\right)$ and tetramethylsilane was used as an internal standard for the ${ }^{1} \mathrm{H}$-NMR study.

\section{TGA}

The thermal stabilities were determined by recording the thermogravimetric traces (Pyris 1 TGA; PerkinElmer, Waltham, MA, USA) in a nitrogen atmosphere using the powdered samples. A heating rate of $10{ }^{\circ} \mathrm{C} \cdot \mathrm{min}^{-1}$ from $35^{\circ} \mathrm{C}$ to $600{ }^{\circ} \mathrm{C}$ and a sample size of $(10 \pm 2) \mathrm{mg}$ were used in each experiment. All pan bases were ensured to be perfectly covered while placing the samples. The balance arm was maintained in a horizontal reference position at the beginning. Changes in the sample mass caused the beam to tilt, which was detected by one of the photoelectric cells. The TGA curve was obtained by recording the mass change and the temperature continuously as a function of time.

\section{RESULTS}

The means and the standard deviations of the flexural strength of the control groups and the copolymer groups are shown in Table 3 . The control groups showed the lowest flexural strength values. The Qc-5 and Qc-10 copolymer groups did not show any differences from the Qc-c group $(P>0.01)$. The Qc-15 copolymer group showed a significant increase compared to the Qc-c group $(P<0.01)$.
Table 3 Means and standard deviations of transverse strength of the control and copolymer groups

\begin{tabular}{|c|c|c|}
\hline \multirow[b]{2}{*}{ Test groups } & \multicolumn{2}{|c|}{ Acrylic resins } \\
\hline & QC-20 & Acron MC \\
\hline Control (100\% PMMA) & $106.05 \pm 7.68$ & $98.07 \pm 2.95$ \\
\hline $\begin{array}{l}\text { 5\% copolymer } \\
\qquad(5 \% \text { AAm }+95 \% \text { PMMA) }\end{array}$ & $109.42 \pm 6.83$ & $99.11 \pm 3.54$ \\
\hline $\begin{array}{l}\text { 10\% copolymer } \\
(10 \% \text { AAm+90\% PMMA) }\end{array}$ & $108.95 \pm 4.92$ & $106.61 \pm 1.95 *$ \\
\hline $\begin{array}{l}\text { 15\% copolymer } \\
(15 \% \text { AAm+85\% PMMA) }\end{array}$ & $114.56 \pm 3.05 *$ & $111.76 \pm 4.60 *$ \\
\hline $\begin{array}{l}\text { 20\% copolymer } \\
\qquad(20 \% \text { AAm+80\% PMMA) }\end{array}$ & $106.91 \pm 6.53$ & $100.42 \pm 4.21$ \\
\hline
\end{tabular}

AAm, acrylamide monomer; PMMA, poly(methyl methacrylate).

*Symbol indicates significant differences between control and copolymer groups in each column $(P<0.01)$.

Among the microwave-polymerized resin groups, Ac-10 and Ac-15 showed significant differences compared to the Ac-c $(P<0.01)$. A significant decrease was observed in the $20 \%$ copolymers compared to the $15 \%$ copolymers in both acrylic resins $(P<0.01)$.

The means and the standard deviations of the elastic modulus of the control groups and the copolymer groups are shown in Table 4. The control groups showed the lowest elastic modulus. The $5 \%$ acrylamide incorporation increased the elastic modulus for both acrylic resins, but no significantly difference was observed $(P>0.01)$. Acrylamide incorporation increased the elastic modulus in the Qc-10, Qc-15 and Qc-20 copolymer groups when compared to the Qc-c group $(P<0.01)$.

Similar to the heat-polymerized resins, a significant increase was also observed in the Ac-10, Ac-15 and Ac-20 copolymer groups when compared to the Ac-c group $(P<0.01)$.

The chemical structure of Qc-c and Ac-c polymers and their AAm copolymers were elucidated by ${ }^{1} \mathrm{H}-\mathrm{NMR}$ and shown in Figures 1 and 2.

In the Qc-c group, the $-\mathrm{OCH}_{3}$ protons for MMA can be seen at $3.6 \mathrm{ppm}$, and the signals at approximately $1.9 \mathrm{ppm}$, which belongs to the $-\mathrm{CH}_{2}$ backbone protons and the methyl protons, were ranged between 0.9 and $1.4 \mathrm{ppm}$. In addition to the MMA protons, new peaks appeared in the copolymer spectra. The $-\mathrm{NH}_{2}$ and $-\mathrm{CH}$

Table 4 Means and standard deviations of elastic modulus of the control and copolymer groups /GPa

\begin{tabular}{|c|c|c|}
\hline \multirow[b]{2}{*}{ Test groups } & \multicolumn{2}{|c|}{ Acrylic resins } \\
\hline & QC-20 & Acron MC \\
\hline Control (100\% PMMA) & $2.07 \pm 0.07$ & $2.07 \pm 0.19$ \\
\hline $\begin{array}{l}5 \% \text { copolymer } \\
\text { (5\% AAm+95\% PMMA) }\end{array}$ & $2.37 \pm 0.13$ & $2.40 \pm 0.27$ \\
\hline $\begin{array}{l}10 \% \text { copolymer } \\
\quad(10 \% \text { AAm }+90 \% \text { PMMA })\end{array}$ & $2.99 \pm 0.08 *$ & $2.91 \pm 0.29 *$ \\
\hline $\begin{array}{l}15 \% \text { copolymer } \\
(15 \% \text { AAm }+85 \% \text { PMMA })\end{array}$ & $3.59 \pm 0.21 *$ & $3.55 \pm 0.18^{*}$ \\
\hline $\begin{array}{l}20 \% \text { copolymer } \\
(20 \% \text { AAm }+80 \% \text { PMMA })\end{array}$ & $3.30 \pm 0.14 *$ & $2.86 \pm 0.20 *$ \\
\hline
\end{tabular}

AAm, acrylamide monomer; PMMA, poly(methyl methacrylate).

*Symbol indicates significant differences between control and copolymer groups in each column $(P<0.01)$. 


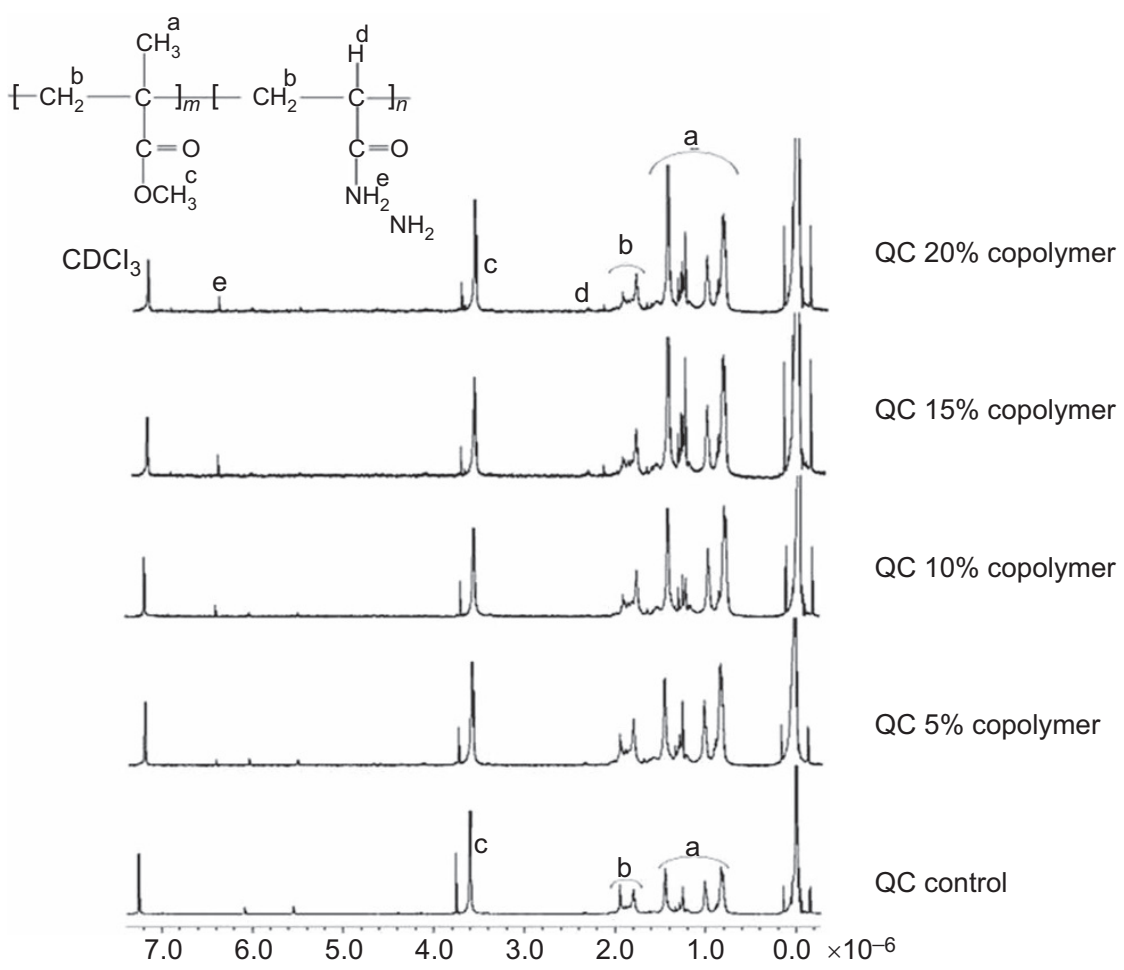

Figure 1 H-NMR spectra of QC control and QC-AAm copolymers. AAm, acrylamide monomer; NMR, nuclear magnetic resonance.

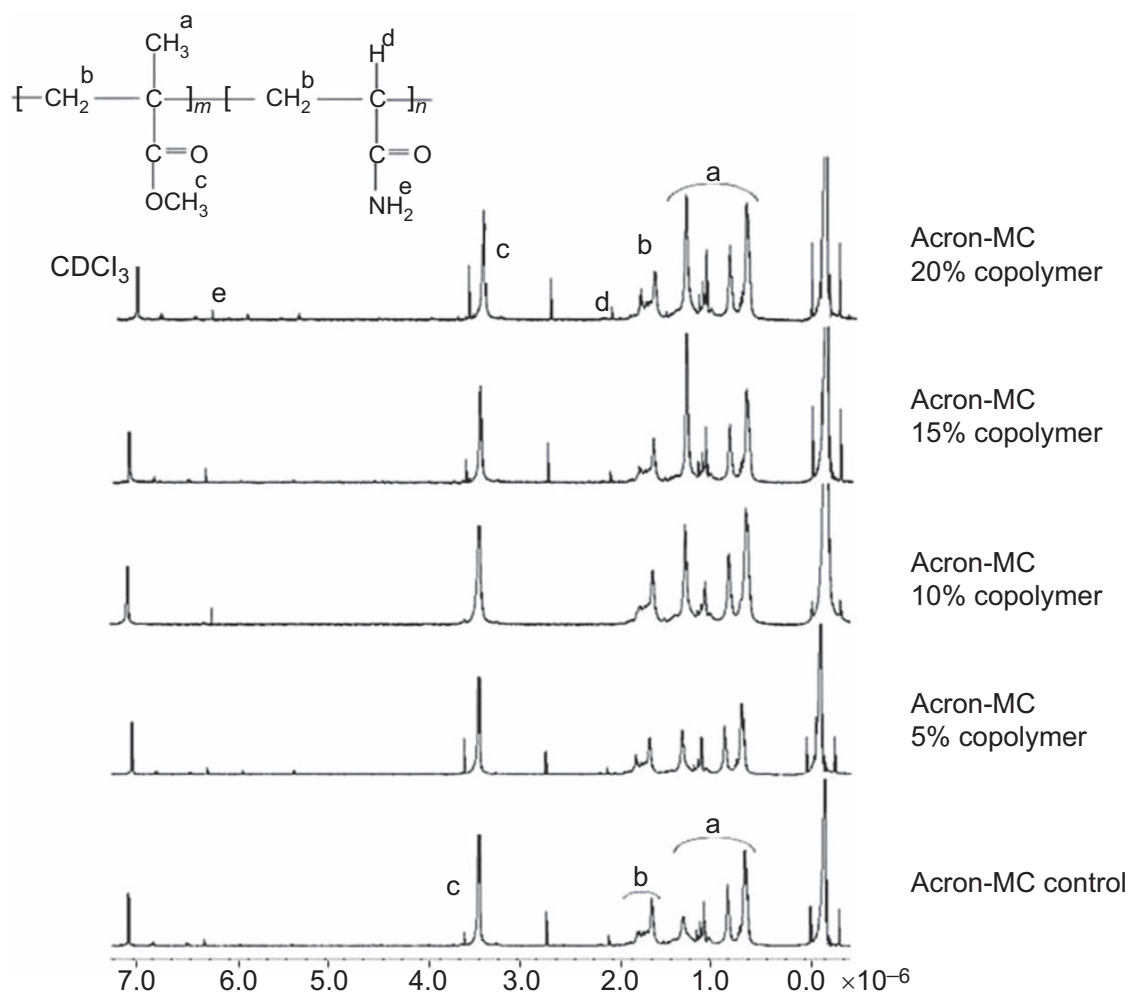

Figure 2 H-NMR spectra of AC control and AC-AAm copolymers. AAm, acrylamide monomer; NMR, nuclear magnetic resonance.

protons can be seen at 6.4 and 2.4 ppm, respectively. The Acron MC control and the copolymer groups showed all characteristic protons that relate to the MMA and AAm units, which is similar to the QC results.
The thermal stabilities of the samples were studied using the TGA method, and the degradation temperatures of both the controls and the copolymers were determined. The TGA thermograms of the Qc-c and Qc-15 groups are shown in Figure 3. 


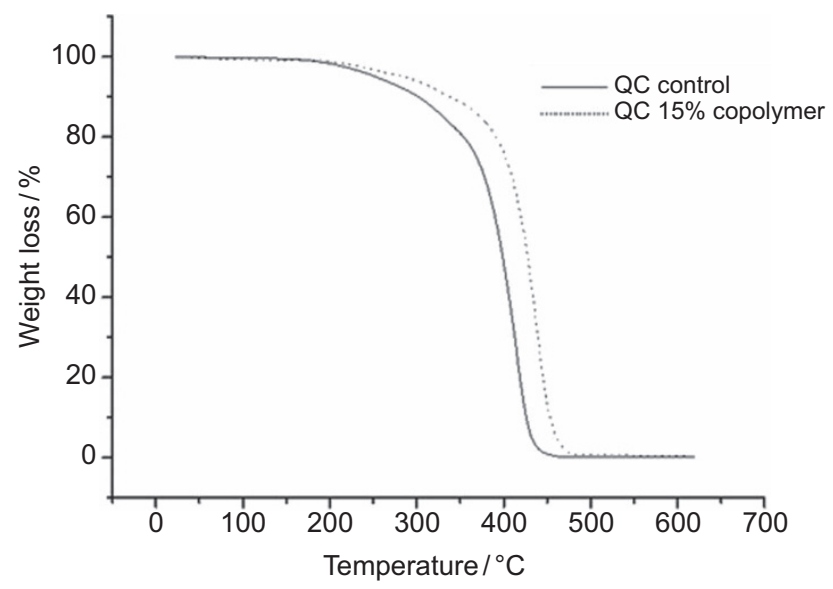

Figure 3 TGA thermogram of QC control and QC-AAm copolymers. AAm, acrylamide monomer; TGA, thermogravimetric analysis.

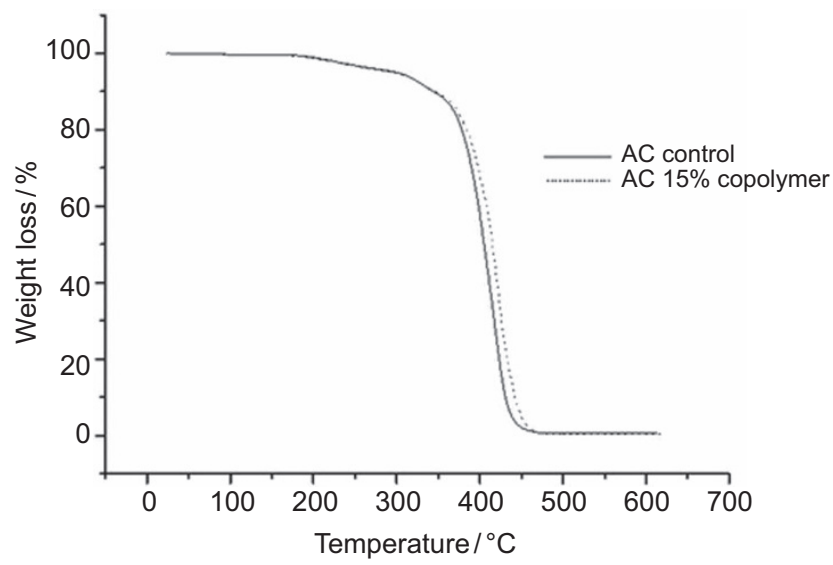

Figure 4 TGA thermogram of AC control and AC-AAm copolymers. AAm, acrylamide monomer; TGA, thermogravimetric analysis.

It is observed that the decomposition temperature of Qc-c $\left(418{ }^{\circ} \mathrm{C}\right)$ shifted to a higher value when the AAm unit (Qc-15: $437{ }^{\circ} \mathrm{C}$ ) was incorporated.

A similar effect of AAm on the thermal stability of the Acron group was observed in Figure 4.

The degradation temperatures of Ac-c and Ac- 15 were measured at $418{ }^{\circ} \mathrm{C}$ and $422{ }^{\circ} \mathrm{C}$, respectively. These results showed that the thermal stability of PMMA is increased when AAm was inserted into the structure.

\section{DISCUSSION}

Fractures, the most common problem in complete dentures, can be prevented by reinforcing the base material. Monomers have been added to conventional denture base resins by various investigators $^{19,21-23}$ for altering the PMMA to optimize and provide improvements in the mechanical properties as it would be desirable to get over the demands of clinical use. This study demonstrated the influence of the copolymerization, which was caused by adding the AAm monomer, on the mechanical properties of PMMA denture base materials. The chemical structure of the PMMA was modified by incorporating the AAm monomer using different proportions and by mixing two different types of monomers to produce a copolymer. The material selected for the current study, acrylamide, was reported as an electroionic monomer that enables chemical reactions and crosslinkings. ${ }^{29}$ AAm possesses a strong ionic interatomic property, which forms its desirable chemical reactivity characteristics. Because it is a dissoluble and colorless material and has good thermal properties, AAm is the material of choice for a wide range of applications. Similar to PMMA, benzoyl peroxide can be added to AAm as an initiator for the polymerization reaction.

The structure of the examined denture base resin is composed of PMMA powder particles and a matrix of monomer liquid. As expected, the modification of the acrylic resin with AAm changed the physical properties. The mechanical properties of the material are known to depend on the ratios of liquid/powder, the crosslinking density of the polymer matrix and the interface between the powder and the matrix. When the polymer powder and the monomer liquid are mixed, the monomers dissolve and diffuse to the surface of the PMMA. ${ }^{30}$ In this study, the liquid monomer also dissolved the AAm monomer particles, so it is possible that adding AAm with different percentages may influence the mechanical properties of the denture material differently.

In this study, it was found that the copolymerization with AAm influenced the flexural strength and the flexural modulus of the denture base polymer. By adding increasing amounts of AAm to the denture base material, a significant change was introduced compared to the control groups of the resins. The mean values of $5 \%$ and $10 \%$ AAm copolymers were higher than the controls for both resins. However, this increase was not statistically significant for Qc-10 when compared to Qc-c, in contrast with the Acron MC. This result may have occurred because of the difference between the control groups of these resins; originally, Qc-c showed a higher flexural strength value than Ac-c. This result may show that a larger amount of monomer could change the polymer matrix saturation for the QC-20 resin. A significant increase was only observed in the $15 \%$ AAm copolymers. In addition, the highest flexural strength values were observed in the $15 \%$ groups for both acrylic resins. While the amount of AAm was increased from $15 \%$ to $20 \%$, a significant decrease occurred. This decrease may be explained by the maximum saturation of the polymer matrix, which was developed by adding the 15\% AAm, and the excess monomer disrupted the crosslinked polymer structure. Furthermore, a longer doughing time was observed in the $20 \%$ copolymer groups when compared to the others. These findings may explain the improper formation of the polymer structure in the $20 \%$ copolymers. Because the presence of small beads in the polymer powder also influences the doughing time and the manipulation time of the resin mixture. ${ }^{31}$ The results of this study may increase the understanding of the properties of acrylic resin dentures and may lead to improvements in the material properties.

In the current study, the flexural strength was evaluated to get an understanding of how denture base resins hold up under function. Information on this parameter is important for clinical application of a denture base material and all results satisfied the criteria in ISO 1567 for denture base resins, which specify that the mean breaking force of acrylic resin should not be less than 55 N. ${ }^{32}$ Previous studies have shown similar results for the control groups of both acrylic resins. Machado et al. ${ }^{7}$ observed a mean flexural strength of $11613 \mathrm{MPa}$ for heat-polymerized PMMA denture base, and Ganzarolli et al. ${ }^{33}$ observed 97.55 MPa for microwave-polymerized PMMA resin. To our knowledge, no previous published report has studied acrylamide addition to PMMA denture base resins. Thus, it is not possible to compare the three-point bending test results of the copolymer groups. 
Although no studies have reported on AAm/PMMA for denture base materials, some reports have evaluated the chemical or physical properties of the AAm/PMMA resins. Endo et al. ${ }^{34}$ were prepared AAm/PMMA using the radical copolymerization reaction and cured the resins, then reported that these resins exhibited a high thermal stability. Zhang and Yarin ${ }^{35}$ evaluated the chemical properties of AAm/PMMA copolymers and concluded that these copolymers possessed covalent bonds that connected all monomers, which enhanced their stability in water. An increase in the degradation temperature of the copolymers compared to the controls was observed in this study, which suggests that the AAm incorporated copolymers can be used to improve the physical properties of the dentures. This conclusion is also supported by the results of three-point bending test. Denture base resins are subjected to thermal changes during the clinical service life. Thermal changes generally occur in the oral cavity because of the temperature of hot or cold food. ${ }^{19}$ In addition, the rebasing and/or relining procedures cause additional polymerization cycles for the prostheses. ${ }^{36}$ The thermal characteristics of the denture base material can have important effects on the dimensional change, the residual monomer content, the degree of conversion and the related physical properties of the denture base resins. ${ }^{19,36}$ In principle, a higher $T_{\mathrm{g}}$ means better thermal stability. ${ }^{37}$

In general, the chemical structure of dental polymers is evaluated using NMR. Umemoto and Kurata ${ }^{38}$ studied the effect of adding different amounts of carbonyl and phenyl methacrylate monomer to PMMA-based denture resins to improve the physical properties. They also analyzed the chemical structures of the control and the copolymer resins using the NMR technique. Likewise, Kurata and Yamazaki ${ }^{39}$ studied the mechanical properties of dental resins using NMR. In this study, the structural characterization of the control and the copolymer resins were investigated using NMR. The control groups of both heat and microwave-activated denture base resins presented similar NMR spectra because both types of resins were PMMA-based. In the NMR spectra of the copolymer resins, new peaks were observed as a result of the AAm monomer. These results confirm that the copolymerization of PMMA and AAm was successfully formed. Additionally, the higher flexural strength, the elastic modulus values and the thermal degradation temperatures can be associated with the copolymerization form.

The limitation of the present study might be the lack of an aging protocol prior to the mechanical testing. The increase in flexural strength and modulus may not be observed after long-term usage of dental prostheses in clinical conditions. Thus, the results of this study should be considered as preliminary mechanical characterization of a new type of reinforcement before clinical application, and further studies are necessary to examine other physical and mechanical properties of the denture base resin. Ultimately, the in vivo performance of the experimental acrylic resins must be considered to propose materials for clinical applications. This part of the work is in progress in our laboratories.

\section{CONCLUSION}

The study of copolymerization by adding a monomer in dental materials provides a reinforcement method, which is expected to optimize the physical properties of the material. This will result in improved dental restorations with aggregated higher quality and durability.

1 Craig RG, Peyton FA. Restorative dental materials. 9th ed. St Louis: Mosby Publishing, 1993.
2 McCord JF. Contemporary techniques for denture base fabrication. J Prosthodont 2009; 18(2): 106-111.

3 Ping-Chaing BK. Polymers in the service of prosthetic dentistry. J Dent 1984; 12(3): 203-214.

4 Nishii M. Studies on the curing of denture base resins with microwave irradiation with particular reference to heat-curing resins. J Osaka Uni Dent School 1968; 2(1): 2340.

5 Jagger DC, Harrison A, Jandt K. The reinforcement of dentures: review. J Oral Rehabil 1999; 26(3): 185-194.

6 Jagger DC, Harrison A, Jandt KD. An investigation of self-reinforced poly(methyl methacrylate) denture base acrylic resin using scanning electron and atomic force microscopy. Int J Prosthodont 2000; 13(6): 526-531.

7 Machado C, Sanchez E, Azer SS et al. Comparative study of the transverse strength of three denture base materials. J Dent 2007; 35(12): 930-933.

8 Valittu PK. Glass fiber reinforcement in repair acrylic resin removable dentures: preliminary results of a clinical study. Quintessence Int 1997; 28(1): 39-44.

9 Zappini G, Kammann A, Wachter WJ. Comparison of fracture tests of denture base materials. J Prosthet Dent 2003; 90(6): 578-585.

10 Uzun G, Hersek N. Comparison of the fracture resistance of six denture base acrylic resins. J Biomater App/ 2002; 17(1): 19-29.

11 Johnston EP, Nicholls JI, Smith DE. Flexure fatigue of 10 commonly used denture base resins. J Prosthet Dent 1981; 46(5): 478-483.

12 John J, Gangadhar SA, Shah I. Flexural strength of heat-polymerized polymethyl methacrylate denture resin reinforced with glass, aramid, or nylon fibers. $J$ Prosthet Dent 2001; 86(4): 424-427.

13 Shimizui H, Mori N, Takahashi Y. Use of metal conditioner on reinforcement wires to improve denture repair strengths. N Y State Dent J 2008; 74(2): 26-28.

14 Narva KK, Valittu PK, Helenius $\mathrm{H}$ et al. Clinical survey of acrylic resin removable denture repairs with glass-fiber reinforcement. Int J Prosthodont 2001; 14(3): 219-224.

15 Valittu PK. Comparison of two different silane compounds used for improving adhesion between fibers and acrylic denture base material. J Oral Rehabil 1993, 20(5): 533-539.

16 Lee HH, Lee CJ, Asaoka K. Correlation in the mechanical properties of acrylic denture base resins. Dent Mater J 2012; 31(3): 157-164.

17 Rodford RA. Further development and evaluation of high impact strength denture base materials. J Dent 1990; 18(3): 151-157.

18 Rodford RA, Braden M. Further observations on high impact strength denture base materials. Biomater 1992; 13(10): 726-728.

19 Ellakwa AE, Morsy MA, El-Sheikh AM. Effect of aluminum oxide addition on the flexural strength and thermal diffusivity of heat-polymerized acrylic resin. $J$ Prosthodont 2008; 17(6): 439-444.

20 El-Charkawi $\mathrm{H}$, El-Said EA, Safouh $\mathrm{HM}$ et al. Effect of addition antimicrobial agents to denture reliners. Egypt Dent J 1994; 40(3): 785-790.

21 Urban VM, Souza RF, Arrais AG et al. Effect of the association of nystatin with a tissue conditioner on its ultimate tensile strength. J Prosthodont 2006; 15(5): 295-299.

22 Cunha TM, Regis RR, Bonatti MR et al. Influence of incorporation of fluoroalkyl methacrylates on roughness and flexural strength of a denture base acrylic resin. $J$ Appl Oral Sci 2009; 17(2): 103-107.

23 Puri G, Berzins DW, Dhuru VB et al. Effect of phosphate group addition on the properties of denture base resins. J Prosthet Dent 2008; 100(4): 302-308.

24 Rubin II. Handbook of plastic materials and technology. New York: John Wiley \& Sons, 1990.

25 Li P, Xu R, Wang W et al. Thermosensitive poly( $\mathrm{N}$-isopropylacrylamide-co-glycidyl methacrylate) microgels for controlled drug release. Colloids Surf B Biointerfaces 2013; 101(1): 251-255.

26 He J, Söderling E, Österbald M et al. Synthesis of methacrylate monomers with antibacterial effects against S. Mutans. Molecules 2011; 16(11): 9755-9763.

27 Cheremisinoff NP. Polymer characterisation laboratory techniques and analysis. Westwood: Noyes Publication, 1996.

28 ISO/DIS 1567 Working Draft 2. Dentistry-denture base polymers. Geneva: International Organization for Standardization, 1997.

29 Okay O, Sarıısık SB, Zor SD. Swelling behavior of anionic acrylamide-based hydrogels in aqueous salt solutions: comparison of experiment with theory. J Appl Polym Sci 1998; 70(3): 567-575.

30 Jordan JM, Rearce EM. Effects of dissolved monomers in the methyl methacrylatea- $\alpha$ methyl styrene copolymer system. J App Polym Sci 1968; 12(6): 1480-1483.

31 Harrison A, Magara JB, Hugget R. The effect of variation in powder particle size on the doughing and manipulation times and some mechanical properties of acrylic resin. Eur J Prosthodont Restor Dent 1995; 3(6): 263-268.

32 ISO/DIS 1567. Specifications for denture base polymers. Geneva: International Organization for Standardization, 1988.

33 Ganzarolli SM, Mello JA, Shinkai RS et al. Internal adaptation and some physical properties of methacrylate-based denture base resins polymerized by different techniques. J Biomed Mater Res B Appl Biomater 2007; 82(1): 169-173.

34 Endo $\mathrm{Y}$, Kawaguchi M, Kato T. Synthesis of poly[(methyl methacrylate)-coacrylamide] modified by titanium-triisopropoxide and their thermal stability. Polymer 2002; 43(14): 3863-3872.

35 Zhang $Y$, Yarin LA. Stimuli-responsive copolymers of $n$-isopropyl acrylamide with enhanced longevity in water for micro- and nanofluidics, drug delivery and nonwoven applications. J Mater Chem 2009; 19(27): 4732-4739. 
36 Yannikakis S, Polychronakis N, Zissis A. Temperature rise during intraoral polymerization of self-cured hard denture base liners. Eur J Prosthodont Restor Dent 2010; 18(2): 84-88.

37 Chen T, Kusy RP. Effect of methacrylic acid: methyl methacrylate monomer ratios on polymerization rates and properties of polymethyl methacrylates. J Biomed Mater Res 1997; 36(2): 190-199.

38 Umemoto K, Kurata S. Basic study of a new denture base resin applying hydrophobic methacrylate monomer. Dent Mater J 1997; 16(1): 21-30.

39 Kurata S, Yamazaki N. Synthesis of dimethacryloxy ethyl-1,1,6,6-tetrahydro perfluorohexamethylene-1,6-dicarbamte as dental base monomers and the mechanical properties of the copolymers of the monomer and methyl methacrylate. Dent Mater J 2011; 30(1): 103-108.

(c) This work is licensed under a Creative Commons

Attribution-NonCommercial-NoDerivative Works 3.0

Unported License. To view a copy of this license, visit http:// creativecommons.org/licenses/by-nc-nd/3.0 